\title{
Solar energy driven photocatalytic membrane modules for water reuse in agricultural and food industries. Pre-industrial experience using $s$-triazines as model molecules ${ }^{\dagger}$
}

\author{
Ignazio Renato Bellobono, ${ }^{1, \ddagger}$ Franca Morazzoni, ${ }^{2}$ Riccardo Bianchi, ${ }^{3}$ \\ Emilia Simona Mangone, ${ }^{1}$ Rodica Stanescu, ${ }^{4}$ Cristina Costache, ${ }^{4}$ \\ and Paola Maria Tozzi ${ }^{5}$ \\ ${ }^{1}$ Environmental Research Centre, University of Milan; via C. Golgi, 19; I-20133 Milan, Italy \\ ${ }^{2}$ Department of Materials Science, University of Milano Bicocca; I-20126, Milan, Italy \\ ${ }^{3}$ CNR, ISTM, Institute of Molecular Sciences and Technologies; I-20133, Milan, Italy \\ ${ }^{4}$ Department of Inorganic Technology and Environmental Protection, \\ Faculty of Industrial Chemistry, Polytechnic University of Bucharest, Romania \\ ${ }^{5}$ R\&D Group, B.I.T. srl; I-20121 Milan, Italy
}

\begin{abstract}
A membrane module, utilizing photocatalytic membranes, has been employed in a pilot plant, in conditions of solar irradiation, to investigate photomineralisation of atrazine, propazine, terbutylazine, symazine, prometryn, and ametryn, as model molecules of $s$-triazine herbicides, at a standard concentration $(1.0 \mathrm{ppm})$ simulating those of contaminated aquifers, by using ozone as oxygen supplier. Photocatalytic composite membranes immobilised $30 \pm 3 \mathrm{wt} . \%$ of $\mathrm{TiO}_{2}$ and $6 \mathrm{wt} . \%$ of a synergic mixture of tri-( $t$-butyl)and tri-(i-propyl)vanadate(V). Photomineralisation was followed by analysis of substrate disappearance, as such, and by total organic carbon (TOC) analysis. A four parameters kinetic model was employed, as set up in previous studies of this series, to interpret the whole photomineralisation curve. Quantum yields, as indicative of catalytic and photocatalytic mechanisms, were evaluated satisfactorily: they are discussed, and compared with those of previous studies on the same substrates, carried out in the same module, but in conditions of practically monochromatic irradiation $(254 \mathrm{~nm})$ within the range of optical absorption of semiconductor. Finally, in order to compare effectiveness of composite photocatalytic membranes, described above, prepared by photografting, either in the presence or in the absence of an added photopromoter, as well as that of metallic membranes, onto which the semiconductor without any photopromoter was present as a 3-4 $\mu \mathrm{m}$ thick surface layer, directly produced on the nanotechnologically treated surface, with those of other commercial materials, parallel experiments were carried out, by using commercial sheets in which the semiconductor was immobilised, by a method based substantially on glueing by colloidal silica. All of these comparison experiments were carried out at a laboratory scale, by using, in these experiments, dioxygen of air, or ozone as oxygen donors.
\end{abstract}

\section{INTRODUCTION}

In six preceding works of this series [1-6], the $\mathrm{TiO}_{2}$-mediated, pilot-plant photomineralisation of atrazine, propazine, terbutylazine, symazine, prometryn, prometone, and ametryn, as model molecules of $s$-triazine herbicides, was thoroughly studied, onto photocatalytic composite membranes immobilising $30 \pm 3$ wt.\% of $\mathrm{TiO}_{2}$ with or without $6 \mathrm{wt}$.\% of a synergic mixture of tri-( $t$-butyl)- and tri-( $i$-propyl)vanadate(V), as photopromoter of semiconductor photocatalyst. These studies aimed first at demonstrating unequivocally that, while photocatalysed degradation of atrazine, and other triazines, using $\mathrm{TiO}_{2}$ suspensions [7], was unable to destruct the heterocyclic ring, the final product observed being 2,4,6-tri-hydroxy-s-triazine, quantitative

${ }^{\dagger}$ Part 74 of the series "Photosynthetic Membranes"

‡E-mail: ignazio.bellobono@unimi.it; crai@unimi.it mineralization of the latter could be reached, on the contrary, onto membranes immobilising the semiconductor [4, 6]. Furthermore, by using a conveniently photopromoted semiconductor, more than tenfold quantum yields could be obtained, when employing ozone as oxygen supplier. In all these investigations [1-6], artificial irradiation sources were employed, either monochromatic or polychromatic, within the range of absorption wavelengths of semiconductor and its photopromoters.

The interest towards $s$-triazines as model molecules is due both to their widespread presence in drinking waters and groundwaters, and to the European Drinking Water Directive, which strongly limits their concentration not only in drinking waters themselves, but also in process water of agricultural and food industries. $s$-Triazine derivatives are among the most widely used herbicides, to control broadleaf and grassy weeds, 
as well as other crops [8]. Their environmental presence both in surface [9] and groundwaters [10] has been ascertained. In the current debate on the amendment of the 80/778 European Drinking Water Directive [11], the issue most controversially discussed is the parameter which sets the maximum concentration of any pesticide or herbicide to occur in drinking water at $0.1 \mathrm{ppb}$. This standard has been established some 25 years ago, and is based on the high sensitivity to pesticides shown by aquatic organisms, rather than on more appropriate mammal toxicology. If an assessment approach similar to that adopted by the World Health Organization [12] will prevail everywhere, the limit values for $s$-triazine herbicides in human drinking water will be of a few ppb. This will require, anyway, advanced water purification systems, among which photocatalytic technologies, particularly those based on the use of titanium dioxide semiconductor, have received great attention $[1-7,13,14]$ since about two decades.

In the present paper, an investigation similar to that described in two preceding papers of this series $[1,3]$ was carried out, by using the same pilot plant designed for that study [1,3]. While in that study $[1,3]$ conditions of practically monochromatic irradiation $(254 \mathrm{~nm})$ within the range of optical absorption of semiconductor were employed, in the present work, however, conditions of solar irradiation were adopted, by using artificial solar lamps at a constant radiating power $\left(900 \mathrm{~W} / \mathrm{m}^{2}\right.$ of photocatalytic membrane, $2.4 \%$ of this power resulting in the ultraviolet region, from $360 \mathrm{~nm}$ downwards to about $310 \mathrm{~nm}$ ). Ozone was always employed as oxygen supplier in these pilot plant experiments, by using a saturation column to treat the processed solutions.

Finally, in order to compare effectiveness of composite photocatalytic membranes, described above, prepared by photografting, and immobilising the semiconductor, either in the presence or in the absence of an added photopromoter, as well as that of metallic membranes, onto which the semiconductor without any photopromoter was present as a 3-4 $\mu \mathrm{m}$ thick surface layer, directly produced on the nanotechnologically treated surface, with those of other materials, parallel experiments were carried out, by using also some commercial non woven tissue sheets in which the semiconductor was sandwiched, by a method based substantially on glueing by colloidal silica (no photocatalyst other than $\mathrm{TiO}_{2}$ was present in this case). All of these comparison experiments were carried out at a laboratory scale, by using, in these experiments, dioxygen contained in air, or ozone as oxygen donors.

The $s$-triazine herbicides investigated in the present paper were propazine (6-chloro- $N^{2}, N^{4}$-di-iso-propyl1,3,5-triazine-2,4-diamine) (I), terbutylazine $\left(N^{2}\right.$-tertbutyl- 6 - chloro - $N^{4}$ - ethyl-1, 3, 5 - triazine-2, 4-diamine) (II), symazine (6-chloro- $N^{2}, N^{4}$-diethyl-1,3,5,triazine2,4-diamine) (III), prometryn $\left(N^{2}, N^{4}\right.$-di-iso-propyl-6- methylthio - 1, 3, 5 - triazine - 2, 4 - diamine) (IV), ametryn $\left(N^{2}\right.$ - ethyl- $N^{4}$ - iso-propyl-6 - methylthio-1,3,5-triazine2,4-diamine) (V), and atrazine ( $N^{2}$-ethyl- $N^{4}$-iso-propyl6-chloro-1,3,5-triazine-2,4-diamine) (VI) (IUPAC names between parentheses).

\section{MATERIALS AND METHODS}

2.1. Photocatalytic membranes. Photocatalytic composite membranes (PHOTOPERM ${ }^{\circledR}$ membranes BIT /313 by B.I.T. srl, Milan, Italy), immobilising $30 \pm$ 3 wt.\% of $\mathrm{TiO}_{2}$, were prepared industrially by a pilot plant, as described [1]. In all the membranes used and tested in the present paper during pilot plant experiments, 6 wt.\% of a synergic mixture of tri-( $t$-butyl)and tri-( $i$-propyl)vanadate $(\mathrm{V})$ was co-immobilised with the semiconductor dioxide, as photocatalytic promoter. This kind of membrane had shown excellent performance with respect to integral photomineralisation of atrazine and other $s$-triazines [2, 3]: this performance was about 10 times greater than that exhibited by membranes immobilising $\mathrm{TiO}_{2}$ alone.

In order, however, to compare efficiency of these membranes with that of membranes immobilising $\mathrm{TiO}_{2}$ without any added promoter, also the latter kind of membranes was produced in the pilot plant facility, and tested by means of laboratory scale experiments (see procedures, below), together with metallic membranes (PHOTOMET ${ }^{\circledR}$ membranes BIT/M07 by B.I.T. srl, Milan, I), onto which the semiconductor without any photopromoter was present as a 3-4 $\mu \mathrm{m}$ thick surface layer, directly produced on the nanotechnologically treated surface.

These three kind of membranes, produced bypatented technologies (by B.I.T. srl, Milan, Italy), were compared, at a laboratory scale level, with commercial non woven tissue sheets in which the semiconductor was sandwiched, by a method based substantially on glueing by colloidal silica (no photocatalyst other than $\mathrm{TiO}_{2}$ was present in this case), this commercial material being in fact fully comparable, from the point of view of semiconductor content, either with PHOTOMET ${ }^{\circledR}$ membranes BIT/M07 or with PHOTOPERM ${ }^{\circledR}$ membranes $\boldsymbol{B I T} / \mathbf{3 1 3}$, prepared in the absence of any photocatalytic promoter.

\subsection{Apparatus and procedures}

2.2.1. Pilot plant experiments. The pilot plant experiments were performed by the same PHOTOP$\boldsymbol{E R} \boldsymbol{M}^{\circledR} \boldsymbol{W} \boldsymbol{W}$ module described and illustrated in previous papers [1, 3], notably in runs relative to photodegradation of atrazine and/or other $s$-triazines solutions at pH 1.5-2 [1], employing molecular oxygen, and in those employing ozone as oxygen supplier, at $\mathrm{pH} 4.6-$ $5.4[2,3]$. The lamps, on the contrary, were changed and replaced by solar lamps (by Jelosil, Milan, Italy), emitting $900 \mathrm{~W}$ per $\mathrm{m}^{2}$ of membrane, $2.4 \%$ of this power 
resulting in the ultraviolet region, from $360 \mathrm{~nm}$ downwards to about $310 \mathrm{~nm}$. The absorbed power, as measured actinometrically, within the absorption range of semiconductor (from $395 \mathrm{~nm}$ downwards) was $30 \pm 2 \mathrm{~W}$, corresponding to $(4.89 \pm 0.16) \times 10^{-3}$ Einstein $\cdot \mathrm{min}^{-1}$. The solutions being processed contained $1.00 \mathrm{ppm}$ of $s$-triazines (I-VI) (see Introduction): they were prepared by using partly purified technical products (purity 9395\%), kindly supplied by OXON Italy (Pero, Milan, Italy). The solutions were prepared in ultra pure water (total organic carbon, TOC, content 4-5 ppb) and were continuously saturated with ozone, without any addition of acids or anything else. Ozone, from the ozonizer gas, was dissolved in a saturation column, in series with the reservoir tank of the pilot plant, in such a way as to maintain a concentration of $4-5 \mathrm{~g} / \mathrm{l}$ of this agent in the gas phase of the absorption column, as carried out in previous work [1-3]. No buffer system being added, $\mathrm{pH}$ varied from initial values of 5.1-5.6 to final values of 3.9-4.6 during the runs. The overall volume of the treated solutions, in the photoreactor module and in the reservoir, was $100.0 \pm 0.4 \mathrm{~L}$.

The initial rate $r_{0}$ of disappearance of $s$-triazines as such by photodegradation was evaluated from curves of their concentration vs. time in the linear range. Experiments were repeated for each set of conditions, at constant concentration $C_{0}$ of substrate $(1.00 \mathrm{ppm})$, so that the mean initial rate and its standard deviation could be estimated.

The disappearance of the $s$-triazines, as such, was followed by the technique of solid-phase microextraction (SPME), followed by GC-MS quantitative analysis, described in previous work [16].

In order to study the relationship between rate of $s$-triazines degradation, as such, and the overall rate of organic carbon disappearance, this latter was also followed, by total organic carbon (TOC) analysis. To this purpose, a Shimadzu TOC-W instrument was used, by which the contribution of inorganic carbon present was always evaluated, in order to obtain TOC by difference from total carbon and inorganic carbon determinations. Due to the high sensitivity detector employed and the utilization of ultra pure water for preparation of solutions, determinations were accurate within 2-5 ppb $C$. The instrument was equipped with the ASI-V self sampler.

2.2.2. Laboratory scale experiments. The laboratory-scale photoreactor was the same as that already described [15]. Overall volume of treated solution was $4.000 \pm 0.005 \mathrm{~L}$; the ratio between the overall reacting volume and the apparent, geometrical surface area of the irradiated side of the membrane $3.8 \pm 0.1 \mathrm{~cm}$. A high pressure mercury arc lamp with a nominal power of $0.12 \mathrm{KW}$ was employed, kindly supplied by Chimia Prodotti e Processi (Muggiò, Milan, Italy): it was further provided with a step by step power regulation device, so that power absorbed by the membrane, as determined actinometrically, could be varied between 0.10 and $1.05 \mathrm{~W} \cdot \mathrm{cm}^{-1}$. In all the experiments, it was fixed at $0.10 \mathrm{~W} \cdot \mathrm{cm}^{-1}$, in order to have a power density comparable to that of the solar lamp employed in the pilot plant experiments. The membrane being concentric to the lamp in the photoreactor used, absorbed power per unit length of lamp was also the same, if referred to unit length of membrane. At $0.10 \mathrm{~W} \cdot \mathrm{cm}^{-1}$ the overall power absorbed by the membrane, within the absorption range of immobilized semiconductor, in the experimental conditions of the present work, was $2.50 \mathrm{~W}$, corresponding to $3.67 \times 10^{-6}$ Einstein $\mathrm{s}^{-1}$. Owing to the refrigeration system of the lamp, by means of water circulating in the lamp sheath, made of quartz, mean temperature, during the runs, was $305 \pm 2 \mathrm{~K}$.

2.3. Kinetic modeling. Kinetic modeling was carried out as described in a preceding paper [17].

\section{RESULTS AND DISCUSSION}

3.1. Pilot plant experiments. By employing a kinetic model thoroughly described in preceding papers [17], mineralisation of substrate $\mathbf{S}$ to $\mathrm{CO}_{2}$ was supposed to occur through one single intermediate $\mathbf{I}$, mediating the behaviour of all possible intermediates formed in the way from $\mathrm{S}$ to $\mathrm{CO}_{2}$, following the Scheme (1)

$$
\mathbf{S} \longrightarrow \mathbf{I} \longrightarrow \mathrm{CO}_{2}
$$

and to imply that both $\mathbf{S}$ and $\mathbf{I}$ showed a competitive apparent Langmuirian adsorption on to the immobilized semiconductor, as expressed by apparent adsorption constants $K_{1}$ and $K_{2}$ respectively, while the kinetic constants $k_{1}$ and $k_{2}$ articulate the degradation of $\mathbf{S}$ and $\mathbf{I}$ respectively. When both $k$ and $K$ couples, for substrate and "intermediate", are accessible experimentally, as in the present work, that is when initial rate data, relative to substrate, and TOC as well, have been measured, they may be first treated by the classical LangmuirHinshelwood equation. The respective values derived by the Langmuirian model are unable to describe the whole curve of mineralisation: they may be used, however, as starting values of the model represented by Scheme (1), to draw, from the differential equations of this model, an optimisation of the whole temporal kinetic curves of substrate and TOC, until consistency is reached and the best fitting of experimental curves is obtained.

Treating of experimental data by the model above [17] allows, consequently, to obtain two couples of parameters, $k_{1}$ and $K_{1}, k_{2}$ and $K_{2}$, which fit the whole photomineralisation curve, and not only its initial segment, as the Langmuirian parameters generally do. The very satisfactory fitting of experimental kinetic data by this model, notwithstanding its extreme simplicity, is 


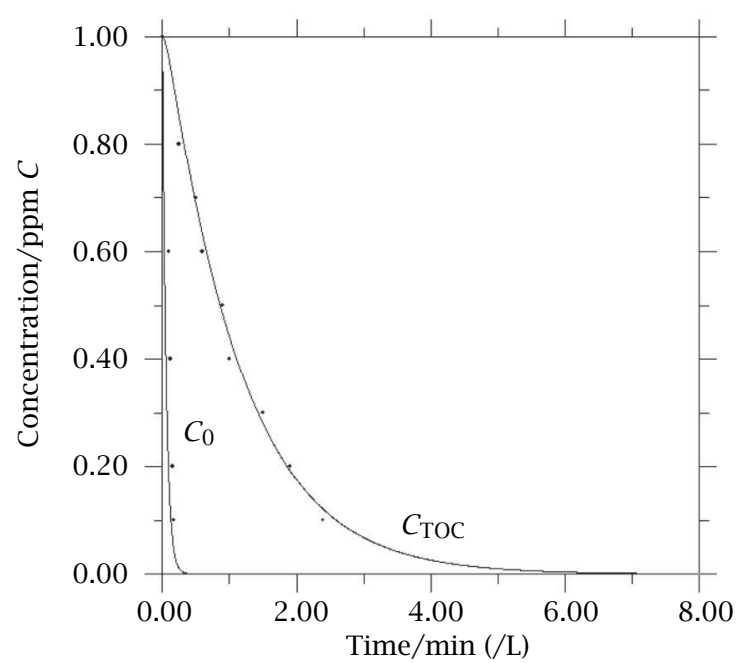

Figure 1. Kinetics of disappearance of atrazine and of its integral photomineralisation in aqueous solution. Curve $C_{0}$ : concentrations, $C_{0} / \mathrm{ppm}$, of atrazine, expressed as carbon, which was not transformed into intermediates, as a function of time, expressed in $\mathrm{min} / \mathrm{L}$, as time necessary to treat $1 \mathrm{~L}$ of solution. Curve $C_{\mathrm{TOC}}$ : concentrations, $C_{\mathrm{TOC}} / \mathrm{ppm}$ of total organic carbon, which was not mineralised, as function of time, expressed in $\mathrm{min} / \mathrm{L}$, as time necessary to treat $1 \mathrm{~L}$ of solution. All the curves refer to the photodegradation of atrazine, in the presence of ozone as oxygen donor (treated volume of aqueous solutions $100.0 \mathrm{~L}$; radiant power of solar lamps absorbed, from $395 \mathrm{~nm}$ downwards, by $2.5 \mathrm{~m}^{2}$ of photocatalytic membranes: $30 \pm 2 \mathrm{~W}$, corresponding to $(4.89 \pm 0.16) \times 10^{-3}$ Einstein $\cdot \mathrm{min}^{-1}$; PHOTOPERM $^{\circledR}$ BIT/313 membranes immobilizing $30 \pm$ $3 \mathrm{wt} . \% \mathrm{TiO}_{2}$ and $6 \mathrm{wt} . \%$ of a synergic mixture of tri-( $t$-butyl)and tri-(i-propyl)vanadate $(V)$ in the PHOTOPERM ${ }^{\circledR}$ WW module [1]).

shown, as an example, in Figure 1 both for the kinetic curves of disappearance of atrazine (I) as such (see Introduction for IUPAC names), and for the TOC disappearance from the atrazine solutions. Similar curves have been obtained for all the other investigates $s$ triazines (II-VI) (see Introduction for IUPAC names).

The optimized values for the two $k$ and $K$ couples above are reported in Table 1 , where also these same parameters are reported, as obtained from another pilot plant study [3], carried out in the same kind of membrane module, but in which radiation absorbed by the semiconductor was substantially monochromatic $(254 \mathrm{~nm})$, even if at a comparable power density as that of the present work, and the volume of solutions treated $1.50 \mathrm{~m}^{3}$.

It may be first observed that, when the $k$ and $K$ couples above are expressed in ppm units, the two series of experiments, relative to previous [3] and present work, even if performed on the same module, with the same kind of membranes, with the same substrates, but in different radiation conditions, and with different overall volumes, apparently give different results concerning the values of these $k$ and $K$ couples. At a first glance, this may be attributed to some difference of behaviour in the two kind of experiments. However, one should bear in mind that in the kinetic model adopted, being a model of a heterogeneous reaction, kinetic constants should be expressed in mass per unit time relatively to the apparent zero order reaction, instead than in concentration per unit time, the latter being dependent on the overall volume. At the light of these observations, the relevance of this fact deserves to be considered as the cause of the difference in the two sets of values. Effectively if these constants are converted in mass per unit time, for example in moles of substrate $\mathbf{S}$ converted or mineralized per unit time, when referring to the first or second step of Scheme (1) respectively for the $k$ parameters, and the same conversion is carried out for the $K$ parameters, the two series of data substantially coincide, as it may be remarked in Table 1 . This stems out obviously from the fact that, as shown unequivocally in all previous work of this series, the kinetic model employed is able to account for all parameters involved in the photocatalytic membrane process, and that no influence of radiation wavelengths or radiation power may ensue, outside that provided for by their rationalisation in this process [19-22].

From all the experimental data, as well from the four kinetic parameters obtained by modeling of pilot plant experiments, the following information may be gained:

(i) As kinetic constants $k$ physically represent, given the kinetic model used for their calculation [17], apparent zero order rate values at "infinite" concentrations of substrate being photodegraded (practically this "infinite" value is reached already at concentrations of the order of 0.001-0.01 M), it immediately appears that the attack of the substrates by hydroxyl or other radicals is one order of magnitude higher than that of intermediates leading ultimately to carbon dioxide, water, and other inorganic anions. Thus, heterocyclic molecules, from this point of view, behave like aromatic ones (see for example ref. [17]), the slow process being that of conversion of intermediates to products.

(ii) At the same time, on the basis of literature criticism [14], as well as of our findings [15, 17-19], the Langmuir-Hinshelwood mechanism should not be credited of general validity, outside its use as a tool, and its formal application to correlate initial rate values, and obtain the couples of parameters above. The criticism on the thermodynamic (adsorption) character of $K$ during photocatalytic experiments [17] is based on the fact that purely kinetic mechanisms yield the same formal mathematical model as that of Langmuir-Hinshelwood. Furthermore, the dependency of $K$ on oxygen donors and on their concentration $[2,15,17,18]$, as well as on operative parameters of treatment plants, such as 
Table 1. Parameters, $k_{1}$ and $K_{1}, k_{2}$ and $K_{2}$ (uncertainties are indicated between parentheses and expressed, relatively to the last digits, as probable errors of the means of optimised values from nine sets of runs at the concentration, or in the range of concentrations, tested), able to fit the whole photomineralisation curve, from disappearance of substrate, to yield intermediates, to formation of carbon dioxide, following Scheme (1), as obtained by optimisation of kinetic curves, by using the set of differential equations corresponding to kinetic model of Scheme (1) [17]. The parameters are expressed in ppm of carbon units (mass of C/volume), or in the corresponding molar units taking into account the volume of treated solutions, and refer to the photodegradation of s-triazines (I-VI) (see Introduction), in the presence of ozone as oxygen donor (treated volume of aqueous solutions $100.0 \mathrm{~L}$; radiant power of solar lamps absorbed, from $395 \mathrm{~nm}$ downwards, by $2.5 \mathrm{~m}^{2}$ of photocatalytic membranes: $30 \pm 2 \mathrm{~W}$, corresponding to $(4.89 \pm 0.16) \times 10^{-3}$ Einstein $\cdot$ min $^{-1} ;$ PHOTOPERM ${ }^{\circledR}$ BIT $/ 313$ membranes immobilizing $30 \pm 3 \mathrm{wt} . \% \mathrm{TiO}_{2}$ and $6 \mathrm{wt} . \%$ of a synergic mixture of tri-(t-butyl)-and tri-(i-propyl)vanadate(V) in the PHOTOPERM ${ }^{\circledR}$ WW module [1]).

\begin{tabular}{lcccccccc}
\hline $\mathbf{S}$ & $\begin{array}{c}k_{1} \\
(\mathrm{ppm} C / \mathrm{min})\end{array}$ & $\begin{array}{c}k_{2} \\
(\mathrm{ppm} C / \mathrm{min})\end{array}$ & $\begin{array}{c}K_{1} \\
(\mathrm{ppm} C)^{-1}\end{array}$ & $\begin{array}{c}K_{2} \\
(\mathrm{ppm} C)^{-1}\end{array}$ & $\begin{array}{c}k_{1} \times 10^{2} \\
(\mathrm{~mol} \mathrm{~S} / \mathrm{min})\end{array}$ & $\begin{array}{c}k_{2} \times 10^{3} \\
(\mathrm{~mol} \mathrm{~S} / \mathrm{min})\end{array}$ & $\begin{array}{c}K_{1} / 10 \\
(\mathrm{M} \mathrm{S})^{-1}\end{array}$ & $\begin{array}{c}K_{2} / 10 \\
(\mathrm{M} \mathrm{S})^{-1}\end{array}$ \\
\hline$(\mathbf{I})$ & $82(3)$ & $5.7(4)$ & $0.26(1)$ & $0.17(1)$ & $8.5(3)$ & $6.8(4)$ & $25(2)$ & $16(2)$ \\
$(\mathbf{I})^{*}$ & $5.3(3)$ & $0.41(3)$ & $3.8(3)$ & $2.6(3)$ & $8.3(4)$ & $6.4(2)$ & $24(5)$ & $17(5)$ \\
$(\mathbf{I I})$ & $88(3)$ & $6.5(2)$ & $0.23(1)$ & $0.19(1)$ & $8.1(4)$ & $6.0(3)$ & $25(2)$ & $21(2)$ \\
$(\mathbf{I I})^{*}$ & $5.8(3)$ & $0.43(3)$ & $3.2(3)$ & $2.6(3)$ & $8.0(4)$ & $6.0(2)$ & $23(4)$ & $19(4)$ \\
$(\mathbf{I I I})$ & $78(6)$ & $6.6(6)$ & $0.20(1)$ & $0.23(3)$ & $7.2(6)$ & $6.1(6)$ & $17(2)$ & $19(4)$ \\
$(\mathbf{I I I})^{*}$ & $5.7(2)$ & $0.48(3)$ & $2.6(3)$ & $3.0(3)$ & $7.9(3)$ & $6.7(2)$ & $19(3)$ & $22(4)$ \\
$(\mathbf{I V})$ & $68(9)$ & $6.2(3)$ & $0.27(2)$ & $0.19(1)$ & $8.1(9)$ & $7.4(3)$ & $23(3)$ & $16(2)$ \\
$(\mathbf{I V})^{*}$ & $4.1(4)$ & $0.43(3)$ & $4.7(4)$ & $3.3(3)$ & $7.4(3)$ & $7.5(4)$ & $26(5)$ & $18(3)$ \\
$(\mathbf{V})$ & $77(3)$ & $5.1(4)$ & $0.29(1)$ & $0.25(2)$ & $7.1(3)$ & $4.7(4)$ & $31(2)$ & $27(3)$ \\
$(\mathbf{V})^{*}$ & $5.1(3)$ & $0.37(4)$ & $4.2(4)$ & $3.9(3)$ & $7.1(4)$ & $5.2(3)$ & $30(5)$ & $28(4)$ \\
$(\mathbf{V I})$ & $74(5)$ & $6.2(5)$ & $0.25(2)$ & $0.27(2)$ & $6.1(5)$ & $5.1(5)$ & $30(3)$ & $32(2)$ \\
$(\mathbf{V I})^{*}$ & $5.5(3)$ & $0.45(3)$ & $3.6(3)$ & $3.8(3)$ & $6.9(3)$ & $5.6(3)$ & $29(4)$ & $31(4)$ \\
\hline
\end{tabular}

*Data taken from ref. [3], and relative to the treatment of $1.50 \mathrm{~m}^{3}$ of $s$-triazines in aqueous solutions.

flow rate [15], gives strong support to this criticism. It is consequently along this line of thought and of interpretation that the general model outlined above is able to fit correctly experimental data. This does not require any implication on the purely thermodynamic significance of $K$, in the traditional sense of adsorption, but rather that the apparent adsorption equilibrium constants $K$, on the light of the most recent interpretation, should be regarded, as ratios of kinetic constants not involving adsorption alone, but also, partly at least, other kinetic processes, which may be influenced by operative parameters of plants. Furthermore, the closeness of $K_{1}$ and $K_{2}$ values in Table 1, as has been observed for aromatic substrates [17], may be equally interpreted as related to this same kind of considerations.

(iii) Otherwise, the great similarity between $k$ values among themselves, pertinent to (I-VI), both for the attack of the substrates and for the degradation of the simulated intermediates, on one side, and between $K$ values, among themselves, with reference to the same $s$-triazines and to the two steps of the kinetic model, on the other side, supports the wholly, or almost wholly, kinetic interpretation of photocatalysis, discussed in (ii), owing to the affinity of molecular structures for the $s$-triazines investigated.

(iv) The fact that $k$ and $K$ values obtained by modeling in the present paper practically coincide with those obtained in different conditions of irradiation in previ- ous work [3] (see Table 1) confirms the general validity of the kinetic model employed, and consequently its suitability to interpret quantum yields as a function of concentration and power density, as has been shown [19-22].

Quantum yields $\Phi_{\infty}$, as reckoned at "infinite" concentration, by $k_{2}$ values of the present work, the corresponding step being the slow process, as discussed in (i) above, are reported in Table 2, in which uncertainties have been calculated by the theory of error propagation. As effective quantum yields $\Phi_{0}$ at a concentration $C_{0}$ depend on concentration [20] following eqn. (2)

$$
\left(1 / \Phi_{0}\right)=\left(1 / \Phi_{\infty}\right)+\left(1 / \Phi_{\infty} K_{2} C_{0}\right)
$$

where the $K_{2}$ is that of the slow step of Scheme (1), in Table 2 the values of $\Phi_{0}$ at a nominal concentration $C_{0}=5.00 \times 10^{-5} \mathrm{M}$, which is near to that experimentally tested, are also reported, together with the percent quantum yield at that concentration, evaluated as the percent ratio between $\Phi_{0}$ values and maximum allowable quantum yields.

Maximum allowable quantum efficiencies $\Phi \max$ may be calculated by stoichiometry and by considering, as a first hypothesis, reactions with $\bullet \mathrm{OH}$ produced from photogenerated holes of semiconductor as the only reactions possible during photomineralisation. This kind of calculation, however, does not take into account any potential scavenging action of conduction band photogenerated electrons by ozone, which has been 
Table 2. Maximum allowable quantum yields, effective quantum yields at "infinite" concentration of substrate, and effective quantum yields at concentration $C_{0}=5.00 \times 10^{-5} \mathrm{M}$ for the photomineralisation of various s-triazines, in aqueous solution, in the presence of ozone, by PHOTOPERM ${ }^{\circledR}$ BIT/313 membranes immobilising $30 \pm 3 \mathrm{wt} . \% \mathrm{TiO}_{2}$ and $6.0 \mathrm{wt} . \%$ of a synergic mixture of tri-( $t$-butyl)- and tri-(i-propyl)vanadate $(V)$ in the PHOTOPERM ${ }^{\circledR}$ WW module [1].

\begin{tabular}{lcccc}
\hline s-Triazines & $\begin{array}{c}\text { Maximum } \\
\text { allowable } \\
\text { quantum yield } \\
\text { (mol/Einstein) }\end{array}$ & $\begin{array}{c}\text { Effective } \\
\text { quantum yield } \\
\text { (mol/Einstein) } \\
\text { at infinite } \\
\text { concentration }\end{array}$ & $\begin{array}{c}\text { Effective } \\
\text { quantum yield } \\
\text { (mol/Einstein) } \\
\times 10^{4} \text { at }\end{array}$ & $\begin{array}{c}\text { Percent quantum } \\
\text { yield (\%) at } \\
C_{0}=5.00 \times 10^{-5} \mathrm{M}\end{array}$ \\
\hline (I) & 0.0143 & 1.39 & 1.13 & 0.79 \\
(II) & 0.0132 & 1.23 & 1.37 & 1.04 \\
(III) & 0.0156 & 1.25 & 1.47 & 0.94 \\
(IV) & 0.0156 & 1.51 & 1.24 & 0.80 \\
(V) & 0.0111 & 0.961 & 1.48 & 1.33 \\
(VI) & 0.0127 & 1.04 & 2.00 & 1.58 \\
\hline
\end{tabular}

shown in previous work (see for example ref. [3]). Moreover, in this calculation, for $s$-triazines, chlorine is supposed to give chloride ions, nitrogen nitrate ions, and sulphur sulphate ions, as most experimental evidence supports $[7,13,14]$. Maximum allowable values of quantum yield calculated by this hypothesis are reported in Table 2 . These values, as may be easily observed by comparison, are about two order of magnitude lower than those experimentally detected, by extrapolation at "infinite" concentration, given that quantum yields, due to the formal mechanism of photocatalysis, decrease with decreasing concentration, following eqn. (2). Of course, one should consider that some uncertainty exists, concerning the hypothesis above of sulphur and nitrogen yielding entirely sulphate and nitrate ions. Nevertheless, even if this is regarded, and the difference in oxidation numbers, say of ammonium with respect to nitrate ions is accounted for, as lower final oxidation states are stated, maximum theoretical values of quantum yields above do not increase other than by a factor less than 2. On the contrary, a possible increasing factor of 4 should be considered for the maximum allowable $\Phi$ max values, if the photocatalytic action of trialkyl vanadates photopromoters is taken into account. If the scavenging action of photopromoter is effective, not only the probability of conduction band electrons recombining with holes is radically decreased or suppressed, but the production of $\bullet \mathrm{O}_{2^{-}}$and $\bullet \mathrm{O}_{2} \mathrm{H}$ radical species (in acid-base equilibrium) is facilitated, by reaction with dissolved oxygen or ozone. If this should take place quantitatively, theoretical maximum quantum yield for the oxidation process, by labile oxygen species thus involved, could increase by a factor of 4 . This is due to the contribution of three further oxidation numbers by $\bullet \mathrm{O}_{2-}$ and $\bullet \mathrm{O}_{2} \mathrm{H}$ radical species, to be added to the contribution of one oxidation number given by $\bullet \mathrm{OH}$ radicals.

To sum up, by a rough estimate, theoretical $\Phi \max$ values may be supposed to be about 8 times greater than those calculated, following the first hypothesis, if a strong photocatalytic action of trialkyl vanadates is assumed, together with a less conservative hypothesis concerning final oxidation states of products deriving from heteroatoms in the triazine molecules. By this way, a final mean value around 0.12 is obtained, which fully rationalizes the experimental value $(0.17)$ measured for atrazine [1] in runs employing oxygen, particularly if sensitization and photoactivation of semiconductor outside its optical absorption range by photocatalytic additives is additionally contemplated [2, 3]. This is already a value by far greater than those usually reported in the literature, as has been already compared and commented [1-3]. It is not unexpected, anyway, to find, as has generally been observed in all germane works of this series, that immobilisation of massive amounts of semiconductor in membranes, such as those used in the present work, in which all active sites of catalysts may be easily and efficiently reached by permeation, is an ideal situation. This state of matters cannot be matched by thin or very thin layers of more or less compact semiconductor, immobilised on a nonpermeable structure, and even less by suspended photocatalysts, to which usual literature data refer. On the contrary, the kind of membranes used in the present work, particularly those promoted by trialkyl vanadates, seem to represent indeed the ideal solution to reach theoretical photocatalytic efficiencies. This stems out, also, indirectly, from the fact that these membranes may act as probes, allowing to determine the values of absolute rate constants of $\bullet \mathrm{OH}$ radicals, generated at the membrane surface or within the membrane pores, with organic substrates, basing on the assumption that the elementary quantum yield for $\bullet \mathrm{OH}$ radicals production is unitary [23]. The latter assumption is abundantly confirmed by the very satisfactory agreement between rate constants got by this new method and those obtained by an independent EPR method established on spin adduct competition.

Yet, when membranes immobilising the trialkyl vanadates promoters are employed, a further factor 


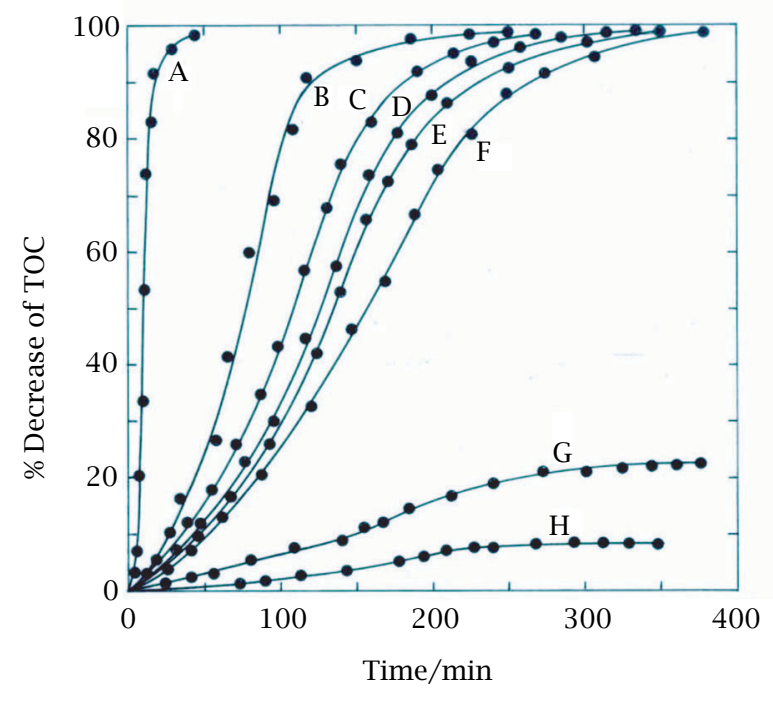

Figure 2. Percent decrease of TOC in $4.00 \mathrm{~L}$ of aqueous solutions containing $1.00 \mathrm{ppm}$ of atrazine, during laboratoryscale experiments (see Experimental Section) by different kinds of photocatalytic membranes (curves A-F), by commercial non woven tissues immobilising $\mathrm{TiO}_{2}$ for comparison (curve $\mathrm{G})$, and in the absence of any photocatalyst (curve $\mathrm{H}$ ). Curve A: PHOTOPERM ${ }^{\circledR}$ BIT/313 composite membranes immobilizing $30 \pm 3 \mathrm{wt} . \% \mathrm{TiO}_{2}$ and 6 wt.\% of a synergic mixture of tri-(t-butyl)- and tri-( $i$ propyl)vanadate( $(V)$, in the presence of ozone as oxygen donor. Curve B: same membrane as that of curve A, but in the presence of air as oxygen donor. Curve C: PHOTOMET ${ }^{\circledR}$ BIT/M07 metallic membrane, nanotechnologically coated by $\mathrm{TiO}_{2}$, in the presence of ozone as oxygen donor. Curve D: PHOTOPERM ${ }^{\circledR}$ BIT/313 composite membranes immobilizing $30 \pm 3 \mathrm{wt} . \% \mathrm{TiO}_{2}$ without any photopromoter, in the presence of ozone as oxygen donor. Curve $\mathrm{E}$ : same membrane as that of curve $\mathrm{C}$, but in the presence of air as oxygen donor. Curve F: same membrane as that of curve $\mathbf{D}$, but in the presence of air as oxygen donor. Curve G: commercial non woven tissues immobilising $\mathrm{TiO}_{2}$, in the presence of air as oxygen donor. Curve $\mathbf{H}$ : photolytic and/or chemical degradation of substrate, in the presence of ozone, without any photocatalyst.

around 12 remains in favour of experimental values, in runs employing ozone. For this, the generalized behaviour shown by $s$-triazines in previous work [2, 3], requires an extra explanation, along the suggested path $[2,3]$ of an efficient catalytic effect of trialkyl vanadates in the non-photocatalytically driven reaction in the presence of ozone, during irradiation, consisting in a catalysed photolysis of ozone, in the presence of vanadium (V) derivatives. This effect may be exerted towards the starting substrate, as well as towards its intermediates, whether photocatalytically produced or not. It may not be ascribed, however, to a purely photolytic or chemical action of ozone towards the sub- strates, which is very modest (contrarily to the hydrogen peroxide photolysis producing hydroxyl radicals when irradiated at wavelengths below $300 \mathrm{~nm}$ ), as has been shown [3] and as will be confirmed in the next section.

3.2. Laboratory-scale experiments. Laboratoryscale experiments have been carried out, by using $4.00 \mathrm{~L}$ of a $1.00 \mathrm{ppm}$ atrazine solution in each run, as described in the Experimental Section. Results, relative to 8 different experimental conditions, are illustrated in Figure 2, in the form of percent decrease of TOC as a function of time. For curve $\mathbf{A}$ a photocatalytic membrane containing 6.00 wt.\% of photopromoter was used in the presence of ozone as oxygen donor; for curve $\mathbf{B}$ this same membrane in the presence of air; for curve $\mathbf{C}$ a metallic membrane immobilizing only the titanium dioxide semiconductor was employed in the presence of ozone; for curve $\mathbf{E}$ this same metallic membrane in the presence of air as oxygen donor; for curve D the standard photocatalytic membrane immobilising only the semiconductor without any photocatalytic promoter was used, in the presence of ozone as oxygen donor; for curve $\mathbf{F}$ this same membrane in the presence of air. For curve $\mathbf{G}$ commercially available non woven tissue sheets were used in which the semiconductor was sandwiched, by a method based substantially on glueing by colloidal silica (no photocatalyst other than $\mathrm{TiO}_{2}$ was present in this case), by utilizing air, as oxygen donor. Finally, in order to evaluate the purely chemical and/or photolytic action of ozone towards the substrate, in the absence of any semiconductor or photocatalytic or catalytic species, for curve $\mathbf{H}$ no membrane or supported catalyst was employed.

As stated above, the purely photolytic or chemical action of ozone towards the triazine molecule is very poor indeed, amounting to a few percent, in terms of TOC mineralization, so that the outstanding efficiency of the photocatalytic membrane immobilizing the trialkyl vanadates, both in rate and in quantitative mineralization capability (curve A), stems out immediately.

The metallic membrane shows an efficiency about $30 \%$ greater than that of the corresponding polymeric membranes, but the difference between the use of ozone and that of dioxygen as oxygen donors is much less important than when the semiconductor is doped by an efficient photopromoting species. In any case, for curves A-F, whether with greater or smaller rate, mineralisation took place smoothly and quantitatively.

On the contrary, for the commercial sample tested (curve G), the rate was more than five times slower than that of the corresponding membrane, that is a membrane with immobilised semiconductor, but without any doping and/or photopromoting species of semiconductor itself (curve F). Furthermore, more importantly, during the run, massive release of titanium 
dioxide and other materials in the treated solution was evident, and consequently the maximum mineralization degree, which could be attained, did not exceed about 20\%, even at longer irradiation times.

\section{CONCLUSIONS}

(I) The outstanding efficiency of photocatalytic membrane processes, onto polymeric membranes immobilising $\mathrm{TiO}_{2}$ and trialkyl vanadates as promoting photocatalysts, and onto metallic membranes immobilising $\mathrm{TiO}_{2}$, with respect to integral photomineralisation of $s$-triazine herbicides in drinking waters, when using ozone as oxygen supplier, is fully confirmed, also in conditions of solar irradiation, which were the main objective and one of the most important aims of the present investigation. Furthermore, modeling of these processes by differential equations deriving from Scheme (1) is validated as fully adequate.

(II) Quantum yields at "infinite" concentration of substrate (1.0-1.5 mol/Einstein; see Table 2) may be interpreted in terms of the very effective role of vanadates as electron scavengers at the irradiated semiconductor surface, as well as of their powerful catalytic action in the non-photocatalytically driven reaction with ozone, during irradiation, not only towards the starting substrate, but particularly towards photoproduced intermediates.

(III) In the presence of ozone as oxygen donor and of trialkyl vanadates as promoters, the rate enhancement due to catalytic effects by production of labile oxygen species, accompanying but independent of the direct performance of radiation (this latter performance concerning: photodegradation by the simultaneous action of radiation and oxygen donor, which amounts only to a few percent; photocatalysis by $\mathrm{TiO}_{2}$, and photocatalysis promoted by vanadates), for all the $s$-triazines examined, corresponds to a factor around 12 with respect to the efficiency of photochemically driven processes alone.

\section{ACKNOWLEDGMENTS}

Some of us (RS and CC) gratefully acknowledge B.I.T. srl (Milan, Italy), in the frame of a permanent agreement with the Polytechnic University of Bucharest, concerning research on B.I.T. patented membranes and processes.

\section{REFERENCES}

[1] I. R. Bellobono, B. Barni, and F. Gianturco, J. Membrane Sci. 102 (1995), 139.

[2] F. Gianturco, C. M. Chiodaroli, I. R. Bellobono, M. L. Raimondi, A. Moroni, and B. Gawlik, Fresenius Environ. Bull. 6 (1997), 461.
[3] I. R. Bellobono, P. L. Pinacci, G. C. Riva, and C. Lagrasta, Fesenius Environ. Bull. 7 (1998), 277.

[4] B. M. Gawlik, A. Moroni, I. R. Bellobono, and H. Muntau, Global NEST 1 (1999), 23.

[5] O. Borio, B. M. Gawlik, I. R. Bellobono, and H. Muntau, Chemosphere 37 (1998), 1033.

[6] A. Moroni, I. R. Bellobono, and B. M. Gawlik, Reaction Kinetics and the Development of Catalytic Processes (G. F. Froment and K. C. Waugh, eds.), Elsevier, Amsterdam, 1999, p. 3885.

[7] E. Pelizzetti, V. Maurino, C. Minero, V. Carlin, E. Pramauro, O. Zerbinati, and M. L. Tosato, Environ. Sci. Technol. 24 (1990), 1559.

[8] C. R. Worthing and S. B. Walzer, The Pesticide Manual: A World Compendium, Thornton Heath, British Crop Protection Council, 1987, p. 36.

[9] R. Frank, B. S. Clegg, C. Sherman, and N. D. Chapman, Arch. Environ. Contam. Toxicol. 19 (1990), 319.

[10] A. Di Corcia, R. Samperi, A. Marcomini, and S. Stellato, Anal. Chem. 65 (1993), 907.

[11] R. Altenburger, Chemosphere 30 (1995), 307.

[12] World Health Organization (WHO), Guidelines for Drinking Water Quality, vol. 1: Recommendations, WHO, Geneva, 1993.

[13] M. Schiavello, Photocatalysis and Environment. Trends and Applications, NATO ASI Ser.C, vol. 237, Kluwer, Dordrecht, 1988.

[14] D. F. Ollis, and H. Al-Ekabi, Photocatalytic Purification and Treatment of Water and Air, Elsevier, Amsterdam, 1993.

[15] B. Barni, A. Cavicchioli, E. Riva, L. Zanoni, F. Bignoli, I. R. Bellobono, F. Gianturco, A. De Giorgi, H. Muntau, L. Montanarella, S. Facchetti, and L. Castellano, Chemosphere 30 (1995), 1847; ibidem 1861.

[16] I. R. Bellobono, C. Lagrasta, M. L. Carbonara, G. Bonizzoni, and P. M. Tozzi, Fresenius Environ. Bull. 12 (2003), 1545.

[17] F. Ascari, I. R. Bellobono, and P. M. Tozzi, Fresenius Environ. Bull. 12 (2003), 2159.

[18] F. Gianturco, L. Vianelli, L. Tatti, F. Rota, P. Bruzzi, L. Rivas, I. R. Bellobono, M. Bianchi, and H. Muntau, Chemosphere 33 (1996), 1531.

[19] L. Rivas, I. R. Bellobono, and F. Ascari, Chemosphere 35 (1997), 2899.

[20] L. Rivas, I. R. Bellobono, and F. Ascari, Chemosphere 37 (1998), 1033.

[21] I. R. Bellobono, C. Lagrasta, M. L. Carbonara, G. Bonizzoni, and P. M. Tozzi, Fresenius Environ. Bull. 12 (2003), 1545.

[22] I. R. Bellobono, F. Morazzoni, R. Bianchi, E. S. Mangone, R. Stanescu, C. Costache, and P. M. Tozzi, Int. J. Photoen., submitted.

[23] R. Morelli, I. R. Bellobono, C. M. Chiodaroli, and S. Alberghetti, J. Photochem. Photobiol. A: Chem. 112 (1998), 271. 


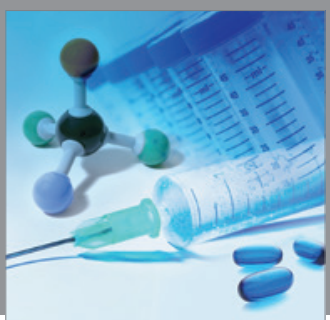

International Journal of

Medicinal Chemistry

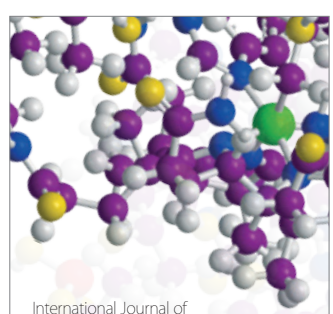

Carbohydrate Chemistry

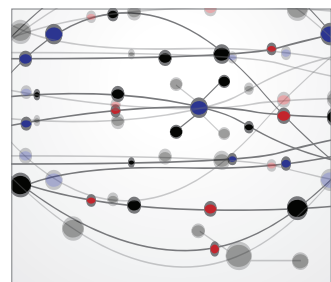

The Scientific World Journal
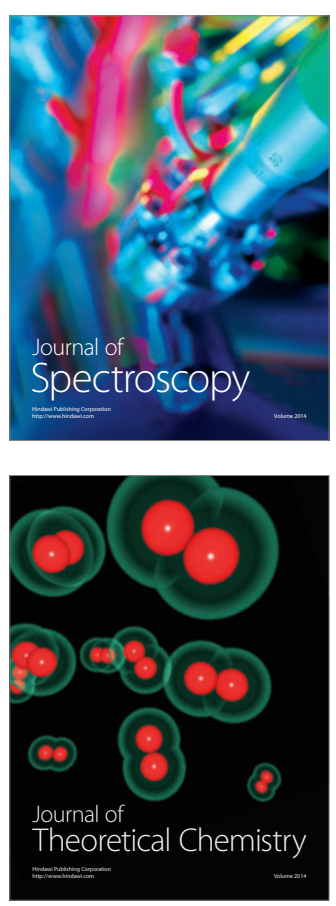
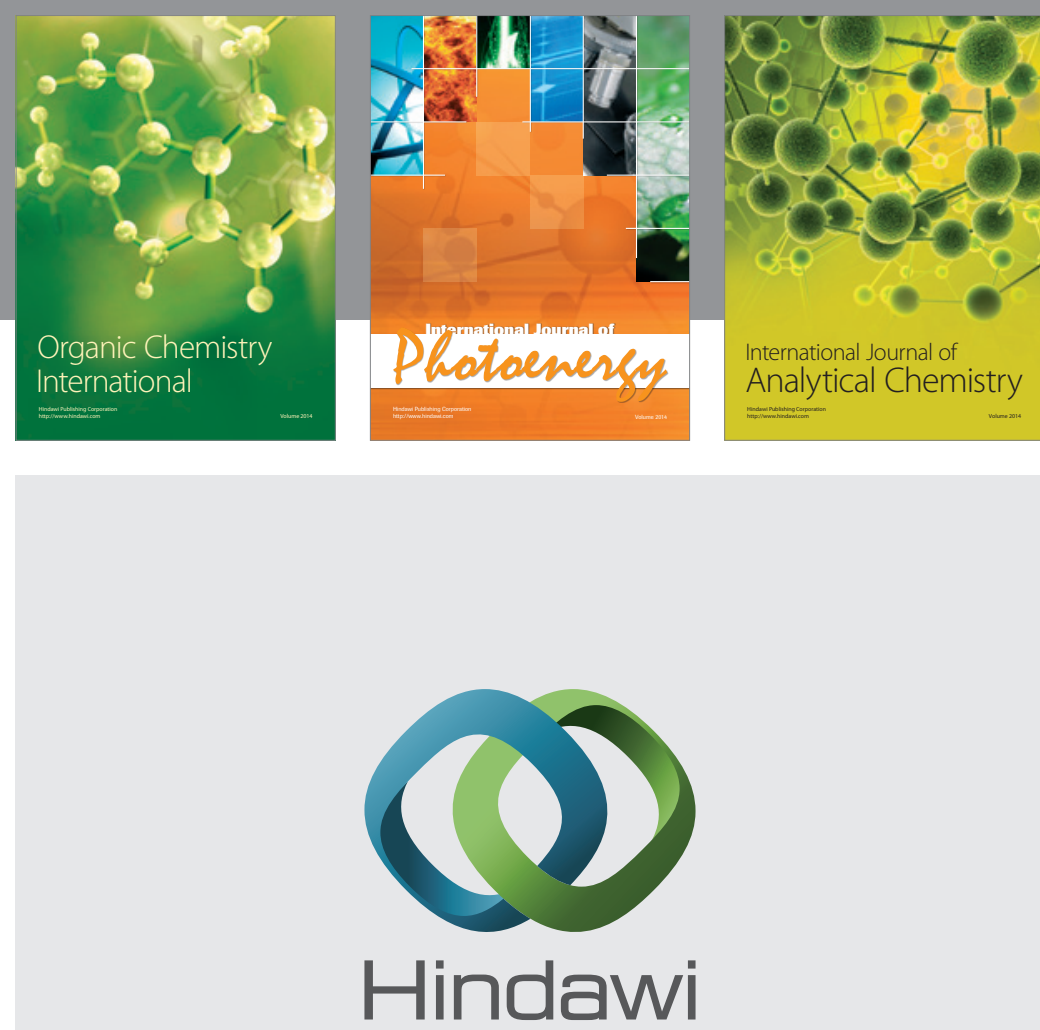

Submit your manuscripts at

http://www.hindawi.com
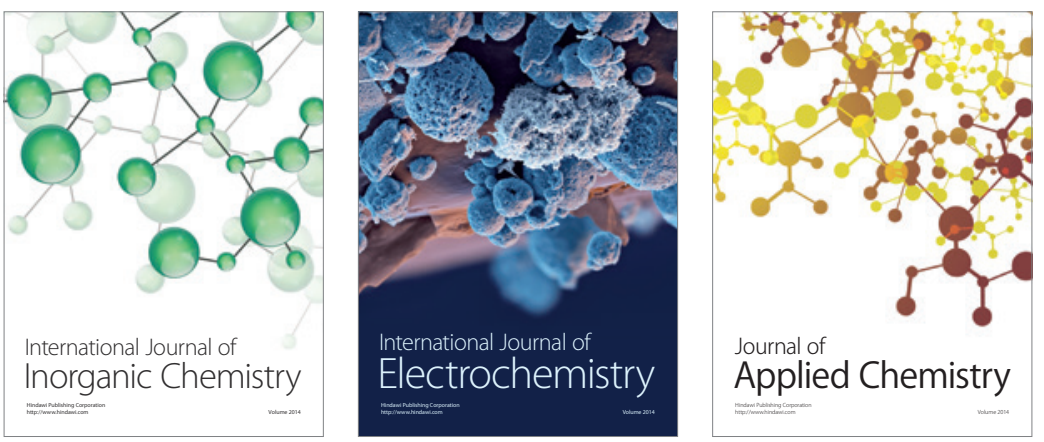

Journal of

Applied Chemistry
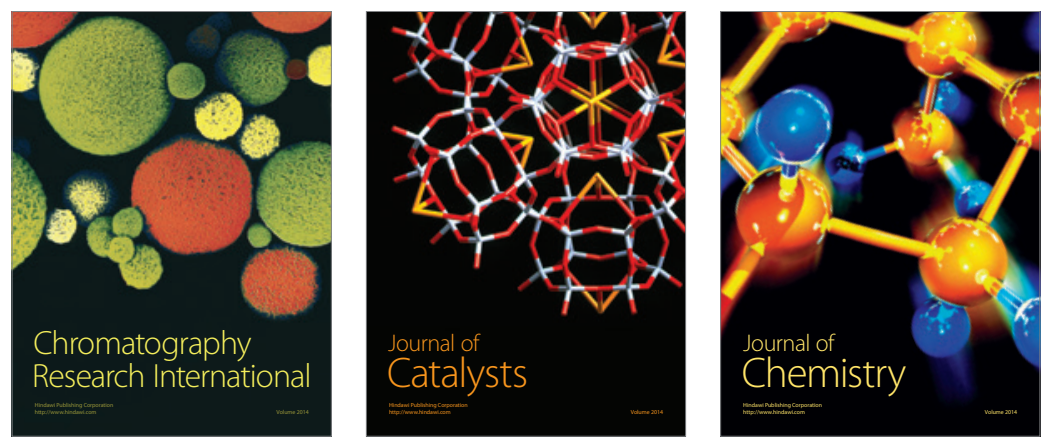
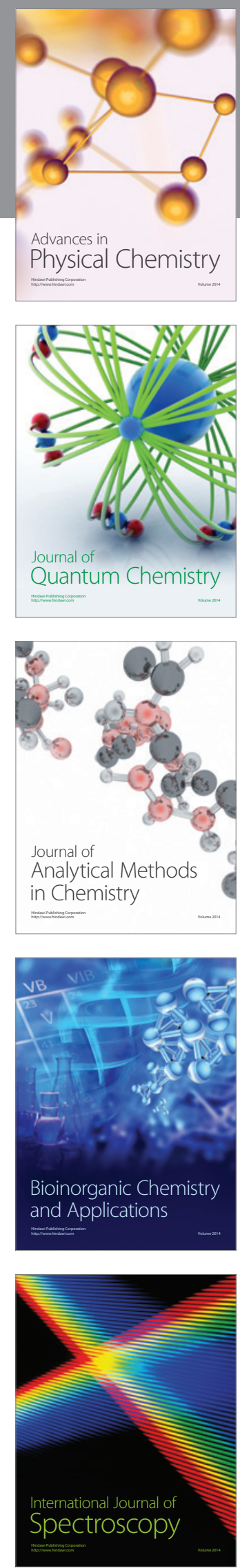